\title{
Reconsideration of Amyloid Hypothesis and Tau Hypothesis in Alzheimer's Disease
}

\author{
Fuyuki Kametani* and Masato Hasegawa* \\ Department of Dementia and Higher Brain Function, Tokyo Metropolitan Institute of Medical Science, Tokyo, Japan
}

The so-called amyloid hypothesis, that the accumulation and deposition of oligomeric or fibrillar amyloid $\beta$ (AB) peptide is the primary cause of Alzheimer's disease (AD), has been the mainstream concept underlying $A D$ research for over 20 years. However, all attempts to develop $A \beta$-targeting drugs to treat $A D$ have ended in failure. Here, we review recent findings indicating that the main factor underlying the development and progression of $A D$ is tau, not $A \beta$, and we describe the deficiencies of the amyloid hypothesis that have supported the emergence of this idea.

\section{OPEN ACCESS}

Edited by:

Naruhiko Sahara,

National Institute of Radiological

Sciences (NIRS), Japan

Reviewed by:

Felix Hernandez,

Consejo Superior de Investigaciones

Cientificas (CSIC), Spain

Tetsuaki Arai,

University of Tsukuba, Japan

${ }^{*}$ Correspondence:

Fuyuki Kametani

kametani-fy@igakuken.or.jp

Masato Hasegawa

hasegawa-ms@igakuken.or.jp

Specialty section:

This article was submitted to

Neurodegeneration,

a section of the journal

Frontiers in Neuroscience

Received: 08 November 2017

Accepted: 12 January 2018

Published: 30 January 2018

Citation:

Kametani F and Hasegawa M (2018)

Reconsideration of Amyloid

Hypothesis and Tau Hypothesis in

Alzheimer's Disease.

Front. Neurosci. 12:25.

doi: 10.3389/fnins.2018.00025
Keywords: Alzheimer's disease, A $\beta$, APP, amyloid, tau, PHF

\section{INTRODUCTION}

Alzheimer's disease (AD) is said to account for about $70 \%$ of dementia. The affected brain exhibits astroglyosis, nerve cell atrophy and neuronal loss, and is characterized by the extensive distribution of two kinds of abnormal structures: so-called senile plaques and neurofibrillary tangles (NFTs). In the 1980's, it was shown that senile plaque consists of amyloid fibrils composed of the amyloid $\beta$ (A $\beta$ ) peptide (Glenner and Wong, 1984; Masters et al., 1985), while NFT contain bundles of paired helical filaments of the microtubule-associated protein tau by immunochemically (Brion et al., 1985; Grundke-Iqbal et al., 1986; Nukina and Ihara, 1986) and biochemically (Goedert et al., 1988; Kondo et al., 1988; Kosik et al., 1988; Wischik et al., 1988b).

$\mathrm{A} \beta$ is a peptide consisting of about 40 amino acids, formed by sequential cleavages of amyloid $\beta$ precursor protein (APP, http://www.uniprot.org/uniprot/P05067) by $\beta$-secretase (BACE 1) and $\gamma$-secretase (a complex containing presenilin 1), as illustrated in Figure 1. APP is a transmembrane protein associated with neuronal development, neurite outgrowth, and axonal transport (Kang et al., 1987). On the other hand, tau is a microtubule-associated protein that promotes microtubule polymerization and stabilization, and the abilities are regulated by phosphorylation (http://www. uniprot.org/uniprot/P10636).

Studies of $\mathrm{AD}$ pathogenesis have mostly been focused on how $\mathrm{A} \beta$ and tau form senile plaques and NFTs, respectively, and how these abnormal structures induce neural degeneration and neuronal loss.

\section{THE AMYLOID HYPOTHESIS}

The amyloid hypothesis (also known as the amyloid cascade hypothesis, the $\mathrm{A} \beta$ hypothesis, etc.) has been the mainstream explanation for the pathogenesis of $\mathrm{AD}$ for over 25 years (Hardy and Allsop, 1991; Selkoe, 1991; Hardy and Higgins, 1992; Hardy and Selkoe, 2002), and may be briefly summarized as follows (Figure 1). In normal subjects, $A \beta$ is excised from APP by $\beta$ - and $\gamma$-secretase and released outside the cell, where it is rapidly 


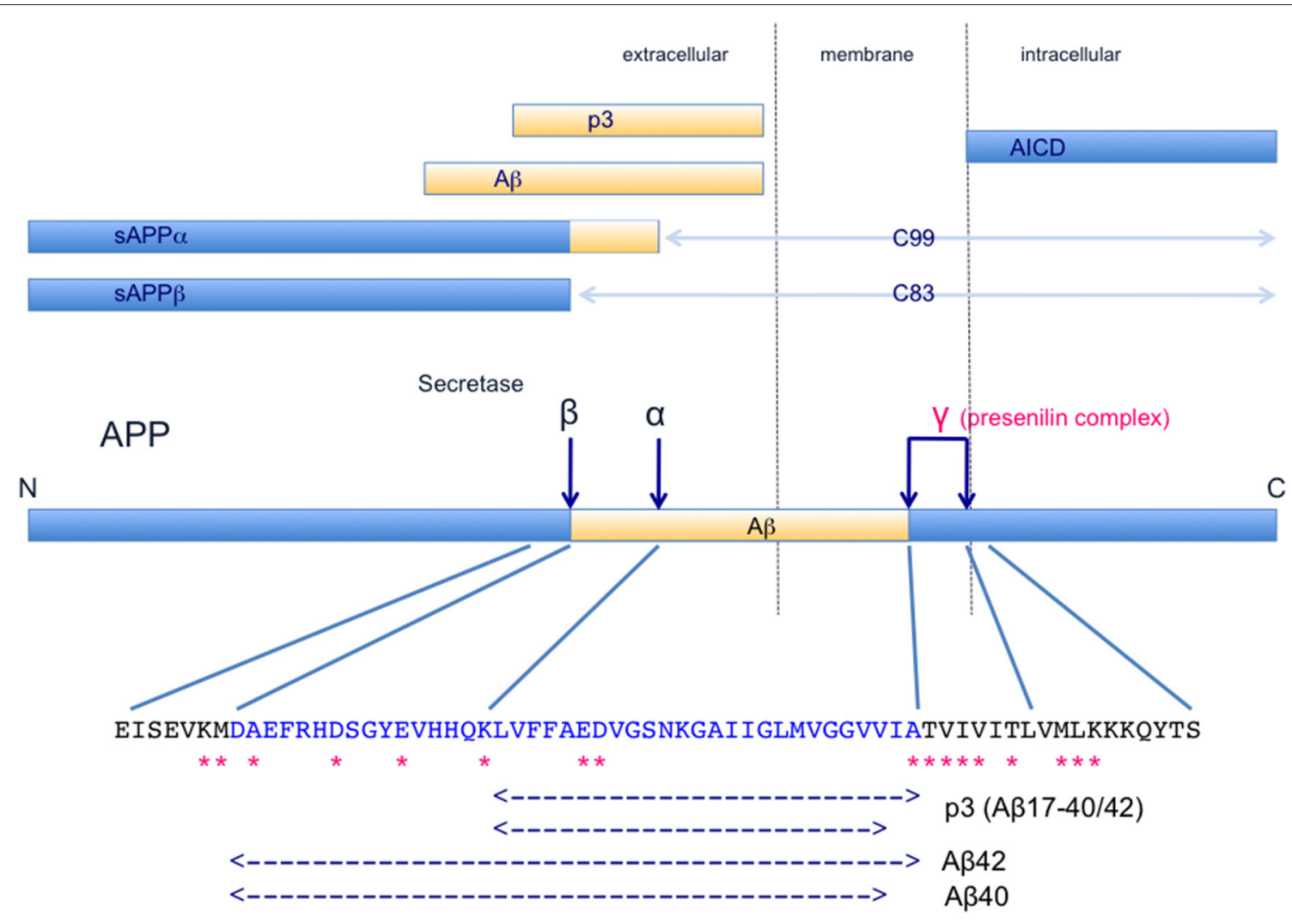

FIGURE 1 | Schematic illustration of the structure and metabolism of APP and its derivatives. Dark blue arrows indicate cleavage sites. $\alpha$-Secretase (TACE/ADAM) (Buxbaum et al., 1998; Lammich et al., 1999) cleaves the $\alpha$-site and $\beta$-secretase (BACE1, Vassar et al., 1999) cleaves the $\beta$-site, affording $N$-terminal fragments, SAPP $\alpha$ and SAPP $\beta$, and C-terminal fragments, C83 and C99, respectively. C83 and C99 are further cleaved at the $\gamma$-sites by $\gamma$-secretase complex, which includes presenilin-1, nicastrin, Aph-1 and Pen2 (Capell et al., 1998; De Strooper et al., 1998; Yu et al., 2000; Francis et al., 2002; Goutte et al., 2002; Takasugi et al., 2003). AICD and $\mathrm{p} 3 / \mathrm{A} \beta$ are produced and released from the membrane. In the normal physiological state, $\alpha$-secretase cleaves $90 \%$ or more of APP and the remaining APP is cleaved by $\beta$-secretase. Therefore, the major products in this APP metabolic pathway are sAPP $\alpha, C 83, p 3$, and AICD, and A $\beta$ is a minor product. AICD is rapidly degraded (Cupers et al., 2001; Kopan and llagan, 2004; Kametani and Haga, 2015). Thus, mutations found in familial AD, especially presenilin mutations, may affect the formation and processing of a variety of products. A part of APP sequence including A $\beta$ is shown. Asterisks indicate APP mutations that have been identified in familial AD. These pathogenetic mutations of APP cluster near the $\alpha$-secretase, $\beta$-secretase and $\gamma$-secretase cleavage sites. These mutations cause accumulation of APP C-terminal fragments (Tesco et al., 2005; Wiley et al., 2005; Xu et al., 2016a), and such accumulation has been found even in sporadic AD brains (Pera et al., 2013). Furthermore, mutations in presenilin, a constitutive protein of the $\gamma$-secretase complex, reduce $\gamma$-secretase activity (Chen et al., 2002; Walker et al., 2005; Bentahir et al., 2006; Shen and Kelleher, 2007; Xia et al., 2015). Decrease in the catalytic capacity of $\gamma$-secretase, which would lead to an increase of APP C-terminal fragments, facilitates the pathogenesis in sporadic and familial AD (Svedruzic et al., 2015).

degraded or removed. However, in aged subjects or under pathological conditions, the metabolic ability to degrade $A \beta$ is decreased, and $A \beta$ peptides may be accumulated. $A \beta 40$ and $\mathrm{A} \beta 42$ (more hydrophobic than $\mathrm{A} \beta 40$ ), containing 40 and 42 amino acid residues, respectively, are major components of the accumulated $A \beta$ (Figure 1). An increase in the level of $A \beta 42$ or an increase in the ratio of $A \beta 42$ induces $A \beta$ amyloid fibril formation, and the accumulated $A \beta$ amyloid fibrils develop into senile plaque, causing neurotoxicity and induction of tau pathology, leading to neuronal cell death and neurodegeneration.

The APP gene is on chromosome 21 (Kang et al., 1987), and the discovery of genetic mutations of APP in early-onset familial $\mathrm{AD}$ (http://www.alzforum.org/mutations), as shown in Figure 1, appeared to support the amyloid hypothesis. These pathogenetic mutations of APP are clustered near $\beta$-secretase or $\gamma$-secretase cleavage sites, and are associated with an increase in $A \beta 42$ production and/or a change in the ratio of $A \beta 42$ formation. Interestingly, Down's syndrome patients with trisomy 21 exhibit AD-like pathology by about 40 years of age (Kolata, 1985), and this was thought to be due to the fact that the amount of APP in the brain was increased to 1.5 times the normal amount and the amount of $A \beta$ was also increased (Kolata, 1985). In addition, APP locus duplication causes autosomal-dominant early-onset $\mathrm{AD}$ with cerebral amyloid angiopathy, with accumulation of large amounts of $\mathrm{A} \beta$ peptides (Delabar et al., 1987; RoveletLecrux et al., 2006). Moreover, other familial AD mutations have been identified in presenilin $1 / 2$, which is a component of $\gamma$-secretase (http://www.alzforum.org/mutations) (Figure 1). These mutations in APP and presenilin are closely linked to the $\mathrm{A} \beta$ production process, providing a rational basis for the idea that $A \beta$ production and/or $A \beta$ amyloid fibril formation represent the 
central pathogenic cause of AD (Hardy and Allsop, 1991; Selkoe, 1991; Hardy and Higgins, 1992; Hardy and Selkoe, 2002).

\section{PROBLEMS WITH THE AMYLOID HYPOTHESIS}

To investigate the pathogenesis of $\mathrm{AD}$, a number of genetically modified mouse models were produced in which $A \beta$ is deposited in the brain. However, although senile plaques (accumulation of $A \beta$ amyloid fibrils) are formed in these mice, NFT formation (accumulation of tau) and nerve cell death have not been observed (Bryan et al., 2009) (http://www.alzforum.org/researchmodels/alzheimers-disease). This suggested that extracellular accumulation of $A \beta$ fibrils is not intrinsically cytotoxic, and also that $A \beta$ does not induce tau accumulation. $A s A \beta$ is a normal metabolic product of APP and is not itself toxic under normal physiological conditions, the idea developed that $\mathrm{A} \beta$ oligomers (multimers) were the key toxic agents.

It has been reported that synaptic failures occur from an early stage in the $\mathrm{AD}$ brain and that the levels of synaptic proteins change (Masliah et al., 2001). Also, a drastic decrease in the number of synapses is characteristically observed in $\mathrm{AD}$ (Davies et al., 1987). Therefore, it was suggested that $\mathrm{A} \beta$, which is present abundantly at an early stage after birth in $\mathrm{AD}$ model mice, causes synaptic impairment (William et al., 2012). Furthermore, it was reported that decrease of dendritic spines, inhibition of long-term potentiation, promotion of long-term suppression, and impairment of memory learning occur when $\mathrm{A} \beta$ oligomers (dimers) obtained from $\mathrm{AD}$ patients' brains were directly transferred to hippocampus of mouse brain (Shankar et al., 2008). However, although $A \beta$ oligomers and $A \beta$ amyloid fibrils were present in $A \beta 42$-overexpressing BRI2- $A \beta$ mice, and amyloid deposits and formation of senile plaques were observed in the brain, degeneration of nerve cells and neuronal loss were not observed, and there was no impairment of cognitive functions (Kim et al., 2007, 2013). These results indicate that $\mathrm{A} \beta 42$, including its oligomers and amyloid fibrils, is not cytotoxic. In addition, various immunotherapies targeting $A \beta$ in $\mathrm{AD}$ model mice were effective in decreasing $\mathrm{A} \beta$ deposition in the brains, but it did not lead to improvement of actual symptoms or accumulation of tau (Ostrowitzki et al., 2012; Giacobini and Gold, 2013; Doody et al., 2014; Salloway et al., 2014).

Recent advances in amyloid imaging have made it possible to observe $A \beta$ amyloid accumulation in the patient's brain. As a result, it has been found that there are many normal patients with amyloid deposits, and also $\mathrm{AD}$ patients with very few amyloid deposits (Edison et al., 2007; Li et al., 2008). Further, in the brain of elderly non-demented patients, the distribution of senile plaques is sometimes as extensive as that of dementia patients (Davis et al., 1999; Fagan et al., 2009; Price et al., 2009; Chetelat et al., 2013). This suggests that $A \beta$ amyloid deposition is a phenomenon of aging, and has no direct relation with the onset of $\mathrm{AD}$.

Taking these facts into account, it appears that neurodegeneration/neuronal loss and amyloid deposition are independent, unrelated phenomena (Chetelat, 2013), contrary to the amyloid hypothesis.

\section{RECONSIDERATION OF APP AND PRESENILIN (PS) MUTATIONS IN FAMILIAL AD}

In this section, we will focus on the nature and effects of mutations that are reported to be associated with familial AD.

In the normal physiological state, $\alpha$-secretase cleaves $90 \%$ or more of APP and the remaining APP is cleaved by $\beta$-secretase, then $\gamma$-secretase cleaves the C-terminal region, as shown in Figure 1. The major products of this APP metabolic pathway are sAPP $\alpha, C 83, p 3$, and APP intracellular domain (AICD), and A $\beta$ is a minor product. Moreover, AICD is rapidly degraded (Cupers et al., 2001; Kopan and Ilagan, 2004; Kametani and Haga, 2015), suggesting that APP C-terminal fragments (C83, C99, and AICD) may be toxic and need to be removed (Kametani, 2008; Robakis and Georgakopoulos, 2014). Thus, when considering the effects of familial $\mathrm{AD}$ mutations, the effects on all the major products of APP metabolism should be considered.

$\mathrm{AD}$-associated mutations in PS (PS1), a constituent protein of the $\gamma$-secretase complex, reduce $\gamma$-secretase activity, leading to decreased production of $A \beta$, especially $A \beta 40$ (Chen et al., 2002; Walker et al., 2005; Bentahir et al., 2006; Shen and Kelleher, 2007; Xia et al., 2015). But, as a result, the proportion of $A \beta 42$ increases and $A \beta$ amyloid is formed. At the same time, APP Cterminal fragments that should be cleaved by $\gamma$-secretase are not cleaved, and accumulate in the cell membrane (Chen et al., 2002; Kametani, 2008; Robakis and Georgakopoulos, 2014).

It has also been reported that APP mutation causes accumulation of APP C-terminal fragments (Tesco et al., 2005, p.181; Wiley et al., 2005, p. 205; Xu et al., 2016a) and that the production of APP C-terminal fragment by $\beta$-secretase increases in the brain of patients with sporadic AD (Pera et al., 2013). Moreover, decrease in the catalytic capacity of $\gamma$-secretase, which would promote accumulation of APP C-terminal fragments, might facilitate the development of both sporadic and familial AD with APP mutation (Svedruzic et al., 2015).

Further, $\gamma$-secretase inhibitor may accelerate accumulation of APP C-terminal fragments in brain, if it is used as a therapeutic agent to suppress $A \beta$ production in $\mathrm{AD}$ patients. Notably, the symptoms of $\mathrm{AD}$ worsened in a clinical trial of $\gamma$-secretase inhibitor (Doody et al., 2013).

These indicate that APP C-terminal fragment accumulation closely links to pathogenesis of sporadic and familial AD.

It was previously reported that APP or APP fragments accumulated in dystrophic neurites in AD brains (Ishii et al., 1989) and that the accumulation of APP and its metabolic fragments induced neurotoxicity and vesicular trafficking impairment (Yoshikawa et al., 1992; Kametani et al., 2004; Roy et al., 2005). It has also been reported that synaptic disorders and dendritic dysplasia occur in the absence of $A \beta$ amyloid deposition (Boncristiano et al., 2005), and that C-terminal fragments of APP cause synaptic failure and memory impairment (Tamayev et al., 2012). Furthermore, transgenic mice expressing the C-terminal intracellular domain of APP (AICD) developed Alzheimer's-like symptoms, such as accumulation of phosphorylated tau and memory impairment (Ghosal et al., 2009). Also, accumulation of APP C-terminal fragments triggers the hydrolysis of cAMP, causing impairment of the cAMP/PKA/CREB pathway 
(Kametani and Haga, 2015). Moreover, APP C-terminal fragment accumulation alters the subcellular localization of APP and the distribution of Rab11, and decreases endocytosis and somato-axon transcytosis of LDL (Woodruff et al., 2016), and this affects axonal vesicle trafficking (Szpankowski et al., 2012; Fu and Holzbaur, 2013; Gunawardena et al., 2013). These findings support the idea that APP C-terminal fragment accumulation causes neuronal impairment.

In addition, sAPP $\alpha$ is involved in neurite outgrowth and has a neuroprotective effect (Baratchi et al., 2012), and AICD is involved in signal transduction (Cao and Sudhof, 2001). Thus, multiple APP domains, including the C-terminus, are required for normal nervous system function (Klevanski et al., 2015). Therefore, since APP metabolites play a variety of functions in the brain, impaired APP metabolism may have a range of effects.

Overall, these findings suggest that the trigger of $\mathrm{AD}$ are closely linked to impairments of APP metabolism and accumulation of APP C-terminal fragments, rather than $\mathrm{A} \beta$ production and $\mathrm{A} \beta$ amyloid formation.

\section{THE TAU HYPOTHESIS}

Tau is one of the microtubule-associated proteins that regulate the stability of tubulin assemblies. The human tau gene is localized in chromosome 17. Six tau isoforms are expressed in the adult human brain as a result of mRNA alternative splicing, with or without exons 2, 3, and 10 (Goedert et al., 1989a; Figure 2). Exon 10 contains the microtubule-binding region. Insertion of exon 10 affords 4-repeat (4R) tau isoforms, while 3-repeat (3R) tau isoforms are produced without exon 10 (Figure 2). Adult human brain expresses both $3 \mathrm{R}$ and $4 \mathrm{R}$ tau isoforms, which are located mainly in axons of adult neurons under normal physiological conditions. The tau hypothesis is that the principle causative substance of $\mathrm{AD}$ is tau.

In $\mathrm{AD}$ brains, $3 \mathrm{R}$ and $4 \mathrm{R}$ tau is accumulated in a hyperphosphorylated state in the pathological inclusions (Goedert, 1993; Goedert et al., 1996; Serrano-Pozo et al., 2011; Iqbal et al., 2016). Ultrastructurally, unique twisted fibrils with $\sim 80 \mathrm{~nm}$ periodicity appearing as paired helical filaments (PHFs) or related straight filaments (SFs) are observed (Crowther and Wischik, 1985; Wischik et al., 1988a,b; Crowther et al., 1989; Goedert et al., 1989b; Greenberg and Davies, 1990; Lee et al., 1991). These pathological inclusions are referred to as neurofibrillary tangles (NFTs) if they are formed in neuronal cell bodies, while they are referred to as threads if they are formed in dendrites or axons. These findings suggested that mis-sorting of tau might induce tau pathology (Zempel and Mandelkow, 2014).

Tau pathology is staged according to Braak and Braak (Braak and Braak, 1991), and appears first in the transentorhinal region (stages I and II), then spreads to the limbic region (stages III and IV) and neocortical areas (stages V and IV). This spreading of tau pathology is strongly correlated with the extent of cognitive and clinical symptoms. Recent PET studies have shown that the spatial patterns of tau tracer binding are closely linked to the patterns of neurodegeneration and the clinical presentation in $\mathrm{AD}$ patients (Bejanin et al., 2017; Okamura and Yanai, 2017) and that subjective cognitive decline is indicative of early tauopathy in the medial temporal lobe, specifically in the entorhinal cortex, and to a lesser extent with elevated global levels of $\mathrm{A} \beta$ (Scholl et al., 2016; Schwarz et al., 2016; Buckley et al., 2017). Furthermore, it has been reported that tau lesions occurred earlier than $A \beta$ accumulation (Braak and Del Tredici, 2014; Johnson et al., 2015). Thus, progression of $\mathrm{AD}$ is strongly associated with tau pathology, rather than $A \beta$ amyloid accumulation.

Tau pathologies are also seen in other neurodegenerative dementing disorders, such as frontotemporal dementia and parkinsonism linked to chromosome 17 (FTDP-17), Pick's disease (PiD), progressive supranuclear palsy (PSP), corticobasal degeneration (CBD), argyrophilic grain disease (AGD), tangleonly dementia, and chronic traumatic encephalopathies (CTE) (Iwatsubo et al., 1994; Spillantini et al., 1997, 1998; Hutton et al., 1998; Poorkaj et al., 1998; Buee and Delacourte, 1999; Goedert and Hasegawa, 1999; Lee et al., 2001; Kovacs, 2015) In particular, FTDP-17 patients exhibit many exonic and intronic mutations in the tau gene (http://www.alzforum.org/mutations), resulting in tau accumulation (Spillantini et al., 1997, 1998; Hutton et al., 1998; Poorkaj et al., 1998). These findings suggest that tau abnormalities cause accumulation of tau and degeneration of neurons. In other sporadic cases of tauopathies, including $\mathrm{AD}$, the initial trigger is unclear, but wild-type tau is accumulated.

What is the tau-induced neurodegeneration? In FTDP17, the disease causing tau-mutations cluster near the Cterminal microtubule binding repeat and impair the ability of tau to bind microtubules (Hasegawa et al., 1998), suggesting impairment of the microtubule regulation. Mis-localized tau also induces impairment of microtubule regulation (Zempel and Mandelkow, 2014). These taus form aggregation and fibril seed, and were hyperphosphorylated as described above. Furthermore, the stability of mutant and hyperphosphorylated tau increases compared to the normal tau (Yamada et al., 2015; Bardai et al., 2018). Aberrant interaction of stabilized tau with filamentous actin induces mis-stabilization of actin (Fulga et al., 2007), synaptic impairment (Cabrales Fontela et al., 2017; Zhou et al., 2017; Bardai et al., 2018), and defects in mitochondrial integrity (DuBoff et al., 2012). Therefore, tau pathology causes extensive damage in the cell, such as transport system, cytoskeletal system, signaling system, and mitochondrial integrity.

\section{PROPAGATION OF TAU PATHOLOGY}

In an experimental model of cultured cells and mice, abnormal tau (amyloid-like fibril tau) converts normal tau to an abnormal type. Therefore, it has been hypothesized that tau aggregates form first in a small number of brain cells, from where they propagate to other regions, resulting in neurodegeneration and disease. This hypothesis has recently gained attention because it has been confirmed that tau proliferates and propagates between 


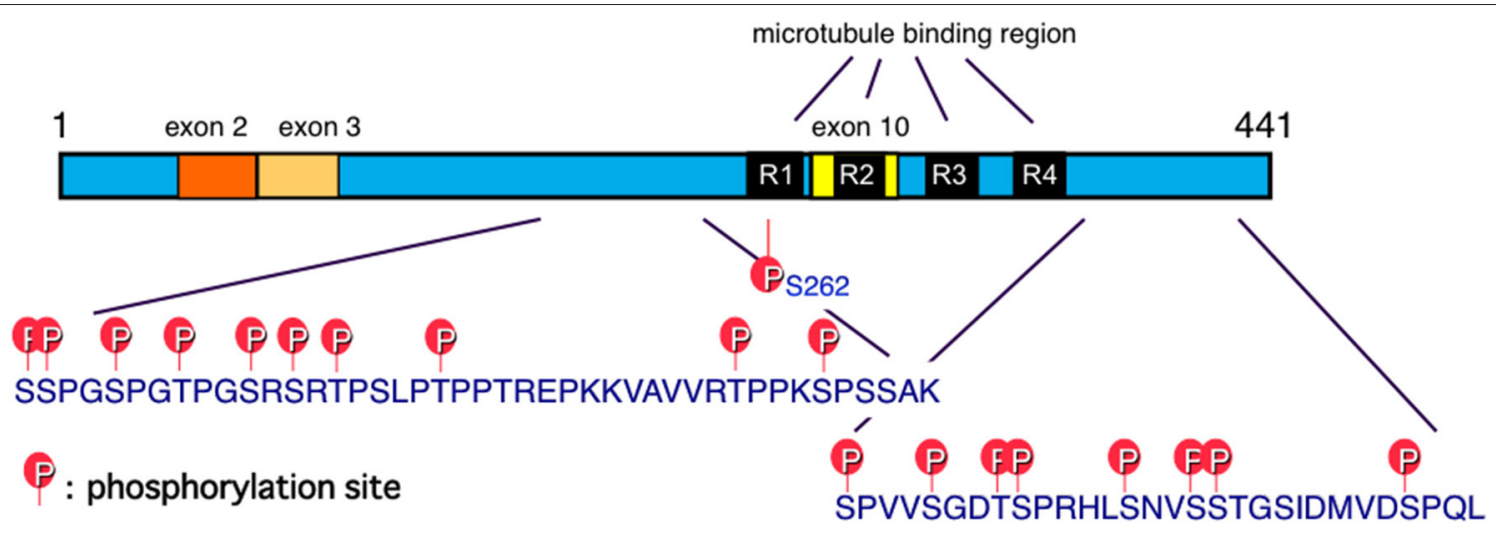

FIGURE 2 | Schematic illustration of functional sites of tau. Six tau isoforms are expressed in the adult human brain as a result of mRNA alternative splicing, with or without exons 2, 3, and 10. Exon 10 contains the microtubule-binding region. Insertion of exon 10 affords 4-repeat (4R) tau isoforms, while 3-repeat (3R) tau isoforms are produced without exon 10 (Goedert et al., 1989a). Major tau phosphorylation sites identified in PHF-tau from AD brains are shown. Microtubule binding regions R3 and R4 form the core of tau fibrils (PHF and SF) (Taniguchi-Watanabe et al., 2016; Fitzpatrick et al., 2017).

cells (Clavaguera et al., 2009, 2013; Nonaka et al., 2010; Hasegawa, 2016; Goedert and Spillantini, 2017). The existence of several human tauopathies with distinct fibril morphologies has led to the suggestion that different molecular conformers (or strains) of aggregated tau exist (Goedert and Spillantini, 2017). Although the transmission mechanism of tau aggregates from cell to cell is still not clear, tau pathology does spread in the brain in a well-defined manner; its distribution can be correlated with the clinical stages of disease (Braak and Braak, 1991), and it is considered that tau pathology correlates better than $A \beta$ pathology with clinical features of dementia. Recently, we found that increase APP with or without familial AD mutations, not $\mathrm{A} \beta$, may work as a receptor of abnormal tau fibrils and promote intracellular tau aggregation (Takahashi et al., 2015), suggesting that APP rather than $A \beta$ may accelerate tau accumulation and propagation.

\section{AD RISK FACTORS, ApoE4 AND TREM2}

Apolipoprotein $\mathrm{E}$ (ApoE) is one of the major apolipoproteins (http://www.uniprot.org/uniprot/P02649). The ApoE gene has three alleles, $\varepsilon 2, \varepsilon 3$, and $\varepsilon 4$, corresponding to isoforms $\mathrm{E} 2$, $\mathrm{E} 3$, and $\mathrm{E} 4$, respectively. In the central nervous system, ApoE produced and secreted by astrocytes and microglia binds to lipoprotein and is taken up into nerve cells via the ApoE receptor during the developmental stage of the central nervous system and the repair period after neuronal damage.

The ApoE4 allele is a genetic risk factor for sporadic $\mathrm{AD}$ (Corder et al., 1993). As the number of $\varepsilon 4$ genes increases, the age of onset of $\mathrm{AD}$ declines and the incidence of $\mathrm{AD}$ increases (Maestre et al., 1995), and there is an increased risk of 3-4 and 8-12 times for one or two copies of the allele, respectively. It is considered that impaired apoE4 function affects the clearance pathway of $\mathrm{A} \beta$ (Zlokovic, 2013; Robert et al., 2017) and modulates $A \beta$-induced effects on inflammatory receptor signaling, including amplification of detrimental pathways and suppression of beneficial pathways (Chan et al., 2015; Tai et al., 2015). To examine the role of ApoE, human ApoE targeted replacement mice were crossed with mutant human amyloid precursor protein (APP) mice. In this context, ApoE genotypes only modulate $A \beta$-mediated insulin signaling impairment (Chan et al., 2015). Recently, however, P301S tau transgenic mice were generated on either a human ApoE knock-in (KI) or ApoE knockout (KO) background, and developed significant brain atrophy primarily in the hippocampus, piriform/entorhinal cortex, and amygdala, accompanied by significant lateral ventricular enlargement (Shi et al., 2017). ApoE plays an important role in regulating tau-mediated neurodegeneration and neuroinflammation, with ApoE4 causing more severe damage and the absence of ApoE being protective (Shi et al., 2017). These findings indicate that ApoE4 affects neurodegeneration independently of $A \beta$ and $A \beta$ amyloid in the context of tau pathology (Shi et al., 2017).

Triggering receptor expressed on myeloid cells 2 (TREM2) is expressed on the membranes of microglia and is critical for the response to injury and AD pathology (http://www.uniprot.org/ uniprot/Q9NZC2). TREM2 recognizes lipoproteins including ApoE, phospholipid and apoptotic cells and is implicated in microglial phagocytosis. Variants in the TREM2 gene increase the risk of getting $\mathrm{AD}$. Initially, this was thought to be related to the elimination of $A \beta$ plaque. TREM 2 deficiency in the setting of pure tauopathy limits gliosis and neuroinflammation, as well as protecting against brain atrophy, suggesting that TREM2 facilitates a microglial response to tau pathology and/or taumediated damage in the brain (Bemiller et al., 2017; Leyns et al., 2017). These results are consistent with the findings of strikingly reduced inflammation and neurodegeneration in mice lacking ApoE, as described above. Therefore, the TREM2-ApoE pathway is important for facilitating the microglial response to damage in the brain, and a functional consequence of activation of the TREM2-ApoE pathway is that microglia lose the ability to regulate brain homeostasis (Krasemann et al., 2017; Ulland et al., 2017). Microglial inflammation promotes 


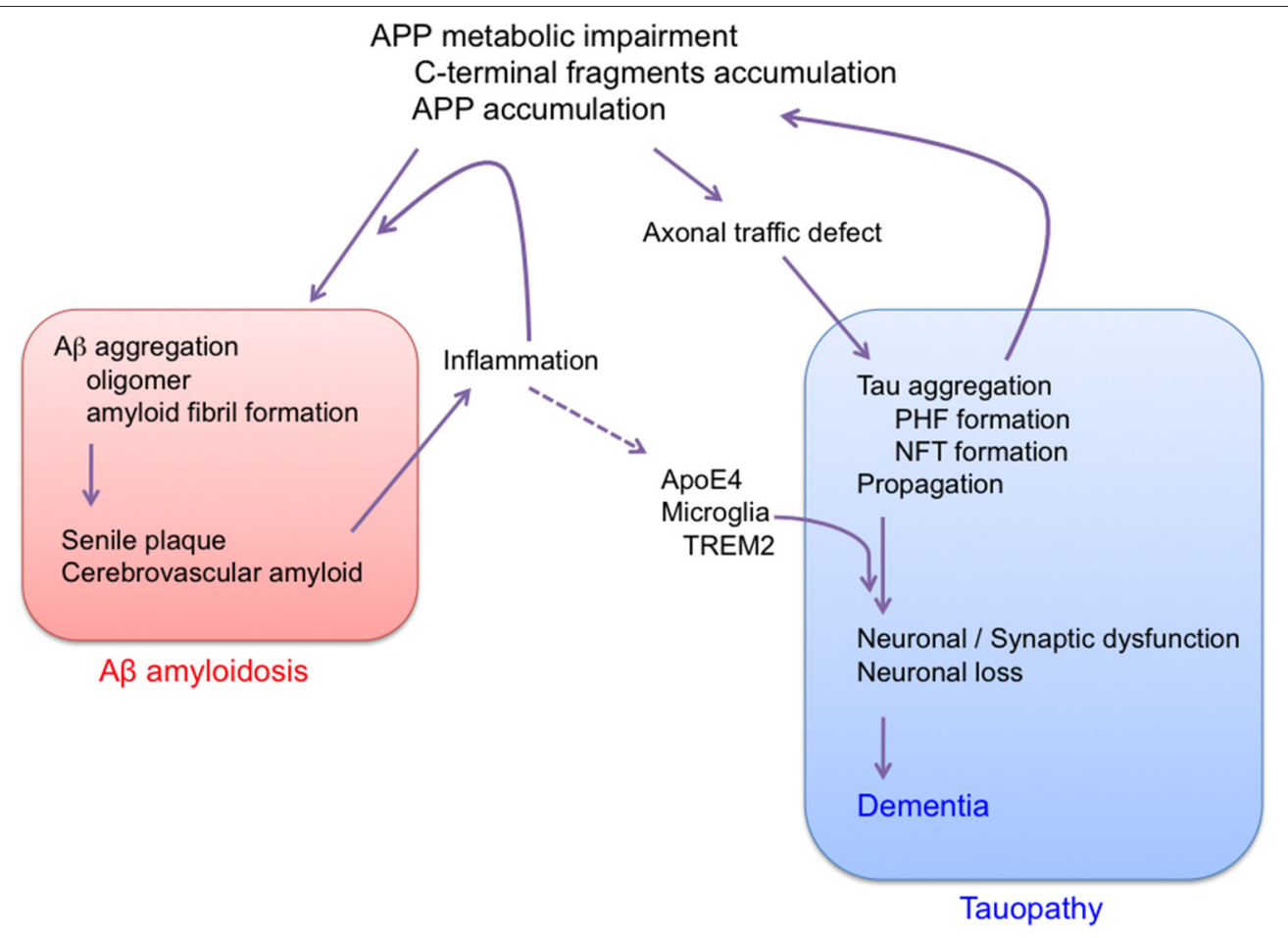

FIGURE 3 | Proposed sequence of major pathogenic events leading to AD. A $\beta$ amyloidosis and tau pathology are regarded as independent pathological events. AD is APP trigger tauopathy.

tau-dependent degeneration independently of $\mathrm{A} \beta$ and $\mathrm{A} \beta$ amyloid.

\section{APP TRIGGER TAUOPATHY}

APP turn over rapidly and easily metabolize (Oltersdorf et al., 1990; Weidemann et al., 2002). Therefore, impairment of APP metabolism has a serious effect on cells. Increased APP and/or its C-terminal fragments induce axonal and synaptic defects (Rusu et al., 2007; Rodrigues et al., 2012; Deyts et al., 2016; Xu et al., 2016b), thereby triggering the mis-localization of tau (Blurton-Jones and Laferla, 2006; Hochgrafe et al., 2013). This protein modulates motility in a motor-specific manner to direct intracellular transport (Chaudhary et al., 2017). Mis-localized tau proteins accumulate, form fibril seeds and propagate ( $\mathrm{He}$ et al., 2017). The pathological tau induce further transport dysfunction (Goldsbury et al., 2006; Rusu et al., 2007), creating a vicious circle and leading to tau accumulation. Moreover, since overexpression of APP promoted the seed aggregation of intracellular tau in cultured cell, suggesting that APP may function as a receptor of abnormal tau fibrils (Takahashi et al., 2015). Thus, increased APP may accelerate pathological incorporation and propagation.

Overall, the results described above suggest that $\mathrm{AD}$ is a disorder that is triggered by impairment of APP metabolism, and that progresses through tau pathology (Figure 3). It is wellknown that $\mathrm{A} \beta$ amyloidosis due to APP metabolic impairment leads to neuroinflammation, which may further affect the progression of tau pathology (Leyns and Holtzman, 2017) So far, there is no evidence that $A \beta$ itself directly affects tau pathology. We cannot rule out the possibility that APP metabolic impairment and tau pathology might be initiated independently in sporadic AD. In any event, there is now convincing evidence that the main factor causing progression of $\mathrm{AD}$ is tau, not $\mathrm{A} \beta$, and that $\mathrm{A} \beta$ amyloidosis and tau pathology should be regarded as independent pathological events. Indeed, it was recently shown that the $\mathrm{AD}$ risk factors ApoE4 and TREM2 are linked to tau pathology (Bemiller et al., 2017; Leyns et al., 2017; Shi et al., 2017). Moreover, the incidence of type 2 diabetes is increased in AD patients (Janson et al., 2004), and it was recently shown that tau protein is involved in the control of brain insulin signaling (Marciniak et al., 2017). Furthermore, the brains of patients with primary age-related tauopathy (PART) contain NFTs that are indistinguishable from those of $\mathrm{AD}$, in the absence of $A \beta$ amyloid plaques (Crary et al., 2014; Duyckaerts et al., 2015; Jellinger et al., 2015). Therefore, tau could contribute to the cognitive and metabolic alterations in patients with $\mathrm{AD}$.

The unexpected failures of all trials of $\mathrm{AD}$ treatment candidate drugs targeting $A \beta$ can easily be understood if the main factor causing progression of $A D$ is tau, not $A \beta$. Indeed, it has already been reported that the suppression or deletion of tau has a profound protective effect against brain damage and neurological deficits (Rapoport et al., 2002; SantaCruz et al., 2005; Roberson et al., 2007; Miao et al., 2010; Shipton et al., 2011; Bi et al., 2017). 
Thus, suppression of tau production currently seems to be the most promising target for development of $\mathrm{AD}$ therapeutic drugs.

\section{CONCLUSION}

The amyloid hypothesis has been the mainstream concept underlying $\mathrm{AD}$ research for over 20 years. However, reconsideration of APP and presenilin (PS) mutations in familial $\mathrm{AD}$ indicate that the trigger of $\mathrm{AD}$ is closely linked to impairments of APP metabolism and accumulation of APP Cterminal fragments, rather than $A \beta$ production and $A \beta$ amyloid formation. Furthermore, all attempts to develop $A \beta$-targeting drugs to treat $\mathrm{AD}$ have ended in failure and recent findings indicating that the main factor underlying the development and progression of $\mathrm{AD}$ is tau, not $\mathrm{A} \beta$. Therefore, $\mathrm{AD}$ is a disorder that is triggered by impairment of APP metabolism, and progresses through tau pathology, not $\mathrm{A} \beta$ amyloid.

\section{REFERENCES}

Baratchi, S., Evans, J., Tate, W. P., Abraham, W. C., and Connor, B. (2012). Secreted amyloid precursor proteins promote proliferation and glial differentiation of adult hippocampal neural progenitor cells. Hippocampus 22, 1517-1527. doi: 10.1002/hipo.20988

Bardai, F. H., Wang, L., Mutreja, Y., Yenjerla, M., Gamblin, T. C., and Feany, M. B. (2018). A conserved cytoskeletal signaling cascade mediates neurotoxicity of FTDP-17 tau mutations in vivo. J. Neurosci. 38, 108-119. doi: 10.1523/JNEUROSCI.1550-17.2017

Bejanin, A., Schonhaut, D. R., La Joie, R., Kramer, J. H., Baker, S. L., Sosa, N., et al. (2017). Tau pathology and neurodegeneration contribute to cognitive impairment in Alzheimer's disease. Brain 140, 3286-3300. doi: 10.1093/brain/awx243.

Bemiller, S. M., McCray, T. J., Allan, K., Formica, S. V., Xu, G., Wilson, G., et al. (2017). TREM2 deficiency exacerbates tau pathology through dysregulated kinase signaling in a mouse model of tauopathy. Mol. Neurodegener. 12:74. doi: 10.1186/s13024-017-0216-6

Bentahir, M., Nyabi, O., Verhamme, J., Tolia, A., Horré, K., Wiltfang, J., et al. (2006). Presenilin clinical mutations can affect gammasecretase activity by different mechanisms. J. Neurochem. 96, 732-742. doi: 10.1111/j.1471-4159.2005.03578.x

Bi, M., Gladbach, A., Van Eersel, J., Ittner, A., Przybyla, M., Van Hummel, A., et al. (2017). Tau exacerbates excitotoxic brain damage in an animal model of stroke. Nat. Commun. 8, 473. doi: 10.1038/s41467-017-00618-0

Boncristiano, S., Calhoun, M. E., Howard, V., Bondolfi, L., Kaeser, S. A., Wiederhold, K. H., et al. (2005). Neocortical synaptic bouton number is maintained despite robust amyloid deposition in APP23 transgenic mice. Neurobiol. Aging 26, 607-613. doi: 10.1016/j.neurobiolaging.2004.06.010

Blurton-Jones, M., and Laferla, F. M. (2006). Pathways by which Abeta facilitates tau pathology. Curr. Alzheimer Res. 3, 437-448. doi: $10.2174 / 156720506779025242$

Braak, H., and Braak, E. (1991). Neuropathological stageing of Alzheimer-related changes. Acta Neuropathol. 82, 239-259. doi: 10.1007/BF00308809

Braak, H., and Del Tredici, K. (2014). Are cases with tau pathology occurring in the absence of Abeta deposits part of the AD-related pathological process? Acta Neuropathol. 128, 767-772. doi: 10.1007/s00401-014-1356-1

Brion, J. P., Passareiro, H., Nunez, J., and Flament-Durand, J., (1985). Mise en évidence immunologique de la protéine tau au niveau deslésions de dégénérescence neurofibrillaire de la maladie d'Alzheimer. Arch. Biol. 95, 229-235.

Bryan, K. J., Lee, H., Perry, G., Smith, M. A., and Casadesus, G. (2009). Transgenic Mouse Models of Alzheimer's Disease: Behavioral Testing and Considerations

\section{AUTHOR CONTRIBUTIONS}

FK and $\mathrm{MH}$, data collection, literature review, manuscript writing.

\section{ACKNOWLEDGMENTS}

This work was supported by Grants-in-Aid for Scientific Research (KAKENHI) JP26117005 (to MH) and JP26293084 (to FK) from the Ministry of Education, Culture, Sports, Science, and Technology, as well as a Grant-in-Aid for Scientific Research (KAKENHI) JP23228004 (to MH) from the Japan Society for the Promotion of Science, and a Grant-in-Aid for Research on Brain Mapping by Integrated Neurotechnologies for Disease Studies (Brain/MINDS) from the Japan Agency for Medical Research and Development (AMED) JP14533254 (to $\mathrm{MH}$ ).

Methods of Behavior Analysis in Neuroscience. Boca Raton, FL: Taylor \& Francis Group, LLC.

Buckley, R. F., Hanseeuw, B., Schultz, A. P., Vannini, P., Aghjayan, S. L., Properzi, M. J., et al. (2017). Region-specific association of subjective cognitive decline with tauopathy independent of global beta-amyloid burden. JAMA Neurol. 74, 1455-1463. doi: 10.1001/jamaneurol.2017.2216

Buée, L., and Delacourte, A. (1999). Comparative biochemistry of tau in progressive supranuclear palsy, corticobasal degeneration, FTDP-17 and Pick's disease. Brain Pathol. 9, 681-693. doi: 10.1111/j.1750-3639.1999.tb00550.x

Buxbaum, J. D., Liu, K. N., Luo, Y., Slack, J. L., Stocking, K. L., Peschon, J. J., et al. (1998). Evidence that tumor necrosis factor alpha converting enzyme is involved in regulated alpha-secretase cleavage of the Alzheimer amyloid protein precursor. J. Biol. Chem. 273, 27765-27767. doi: 10.1074/jbc.273.43.27765

Cabrales Fontela, Y., Kadavath, H., Biernat, J., Riedel, D., Mandelkow, E., and Zweckstetter, M. (2017). Multivalent cross-linking of actin filaments and microtubules through the microtubule-associated protein Tau. Nat. Commun. 8, 1981. doi: 10.1038/s41467-017-02230-8

Cao, X., and Südhof, T. C. (2001). A transcriptionally active complex of APP with Fe65 and histone acetyltransferase Tip60. Science 293, 115-120. doi: $10.1126 /$ science.1058783

Capell, A., Grünberg, J., Pesold, B., Diehlmann, A., Citron, M., Nixon, R., et al. (1998). The proteolytic fragments of the Alzheimer's disease-associated presenilin-1 form heterodimers and occur as a 100-150-kDa molecular mass complex. J. Biol. Chem. 273, 3205-3211. doi: 10.1074/jbc.273.6.3205

Chan, E. S., Chen, C., Cole, G. M., and Wong, B. S. (2015). Differential interaction of Apolipoprotein-E isoforms with insulin receptors modulates brain insulin signaling in mutant human amyloid precursor protein transgenic mice. Sci. Rep. 5:13842. doi: 10.1038/srep13842

Chaudhary, A. R., Berger, F., Berger, C. L., and Hendricks, A. G. (2017). Tau directs intracellular trafficking by regulating the forces exerted by kinesin and dynein teams. Traffic. doi: 10.1111/tra.12537. [Epub ahead of print].

Chen, F., Gu, Y., Hasegawa, H., Ruan, X., Arawaka, S., Fraser, P., et al. (2002). Presenilin 1 mutations activate gamma 42-secretase but reciprocally inhibit epsilon -secretase cleavage of amyloid precursor protein (APP) and S3-Cleavage of Notch. J. Biol. Chem. 277, 36521-36526. doi: 10.1074/jbc.M205093200

Chételat, G. (2013). Alzheimer disease: Abeta-independent processes-rethinking preclinical AD. Nat. Rev. Neurol. 9, 123-124. doi: 10.1038/nrneurol.2013.21

Chételat, G., La Joie, R., Villain, N., Perrotin, A., De La Sayette, V., Eustache, F., et al. (2013). Amyloid imaging in cognitively normal individuals, at-risk populations and preclinical Alzheimer's disease. Neuroimage Clin. 2, 356-365. doi: 10.1016/j.nicl.2013.02.006

Clavaguera, F., Akatsu, H., Fraser, G., Crowther, R. A., Frank, S., Hench, J., et al. (2013). Brain homogenates from human tauopathies induce tau 
inclusions in mouse brain. Proc. Natl. Acad. Sci. U.S.A. 110, 9535-9540. doi: $10.1073 /$ pnas. 1301175110

Clavaguera, F., Bolmont, T., Crowther, R. A., Abramowski, D., Frank, S., Probst, A., et al. (2009). Transmission and spreading of tauopathy in transgenic mouse brain. Nat. Cell Biol. 11, 909-913. doi: 10.1038/ncb1901

Corder, E. H., Saunders, A. M., Strittmatter, W. J., Schmechel, D. E., Gaskell, P. C., Small, G. W., et al. (1993). Gene dose of apolipoprotein E type 4 allele and the risk of Alzheimer's disease in late onset families. Science 261, 921-923. doi: $10.1126 /$ science. 8346443

Crary, J. F., Trojanowski, J. Q., Schneider, J. A., Abisambra, J. F., Abner, E. L., Alafuzoff, I., et al. (2014). Primary age-related tauopathy (PART): a common pathology associated with human aging. Acta Neuropathol. 128, 755-766. doi: 10.1007/s00401-014-1349-0

Crowther, R. A., and Wischik, C. M. (1985). Image reconstruction of the Alzheimer paired helical filament. EMBO J. 4, 3661-3665.

Crowther, T., Goedert, M., and Wischik, C. M. (1989). The repeat region of microtubule-associated protein tau forms part of the core of the paired helical filament of Alzheimer's disease. Ann. Med. 21, 127-132. doi: 10.3109/07853898909149199

Cupers, P., Orlans, I., Craessaerts, K., Annaert, W., and De Strooper, B. (2001). The amyloid precursor protein (APP)-cytoplasmic fragment generated by gamma-secretase is rapidly degraded but distributes partially in a nuclear fraction of neurones in culture. J. Neurochem. 78, 1168-1178. doi: 10.1046/j.1471-4159.2001.00516.x

Davies, C. A., Mann, D. M., Sumpter, P. Q., and Yates, P. O. (1987). A quantitative morphometric analysis of the neuronal and synaptic content of the frontal and temporal cortex in patients with Alzheimer's disease. J. Neurol. Sci. 78, 151-164. doi: 10.1016/0022-510X(87)90057-8

Davis, D. G., Schmitt, F. A., Wekstein, D. R., and Markesbery, W. R. (1999). Alzheimer neuropathologic alterations in aged cognitively normal subjects. J. Neuropathol. Exp. Neurol. 58, 376-388. doi: 10.1097/00005072-199904000-00008

De Strooper, B., Saftig, P., Craessaerts, K., Vanderstichele, H., Guhde, G., Annaert, W., et al. (1998). Deficiency of presenilin-1 inhibits the normal cleavage of amyloid precursor protein. Nature 391, 387-390. doi: 10.1038/34910

Delabar, J. M., Goldgaber, D., Lamour, Y., Nicole, A., Huret, J. L., De Grouchy, J., et al. (1987). Beta amyloid gene duplication in Alzheimer's disease and karyotypically normal Down syndrome. Science 235, 1390-1392. doi: 10.1126/science.2950593

Deyts, C., Clutter, M., Herrera, S., Jovanovic, N., Goddi, A., and Parent, A. T. (2016). Loss of presenilin function is associated with a selective gain of APP function. Elife 5:e15645. doi: 10.7554/eLife.15645

Doody, R. S., Raman, R., Farlow, M., Iwatsubo, T., Vellas, B., Joffe, S., et al. (2013). A phase 3 trial of semagacestat for treatment of Alzheimer's disease. N. Engl. J. Med. 369, 341-350. doi: 10.1056/NEJMoa1210951

Doody, R. S., Thomas, R. G., Farlow, M., Iwatsubo, T., Vellas, B., Joffe, S., et al. (2014). Phase 3 trials of solanezumab for mild-to-moderate Alzheimer's disease. N. Engl. J. Med. 370, 311-321. doi: 10.1056/NEJMoa1312889

DuBoff, B., Götz, J., and Feany, M. B. (2012). Tau promotes neurodegeneration via DRP1 mislocalization in vivo. Neuron $75,618-632$. doi: 10.1016/j.neuron.2012.06.026

Duyckaerts, C., Braak, H., Brion, J.-P., Buée, L., Del Tredici, K., Goedert, M., et al. (2015). PART is part of Alzheimer disease. Acta Neuropathol. 129, 749-756. doi: 10.1007/s00401-015-1390-7

Edison, P., Archer, H. A., Hinz, R., Hammers, A., Pavese, N., Tai, Y. F., et al. (2007). Amyloid, hypometabolism, and cognition in Alzheimer disease: An [11C]PIB and [18F]FDG PET study. Neurology 68, 501-508. doi: 10.1212/01.wnl.0000244749.20056.d4

Fagan, A. M., Mintun, M. A., Shah, A. R., Aldea, P., Roe, C. M., Mach, R. H., et al. (2009). Cerebrospinal fluid tau and ptau(181) increase with cortical amyloid deposition in cognitively normal individuals: implications for future clinical trials of Alzheimer's disease. EMBO Mol. Med. 1, 371-380. doi: 10.1002/emmm.200900048

Fitzpatrick, A. W. P., Falcon, B., He, S., Murzin, A. G., Murshudov, G., Garringer, H. J., et al. (2017). Cryo-EM structures of tau filaments from Alzheimer's disease. Nature 547, 185-190. doi: 10.1038/nature23002

Francis, R., McGrath, G., Zhang, J., Ruddy, D. A., Sym, M., Apfeld, J., et al. (2002). aph-1 and pen-2 are required for Notch pathway signaling, gamma-secretase cleavage of betaAPP, and presenilin protein accumulation. Dev. Cell 3, 85-97. doi: 10.1016/S1534-5807(02)00189-2

Fu, M. M., and Holzbaur, E. L. (2013). JIP1 regulates the directionality of APP axonal transport by coordinating kinesin and dynein motors. J. Cell Biol. 202, 495-508. doi: 10.1083/jcb.201302078

Fulga, T. A., Elson-Schwab, I., Khurana, V., Steinhilb, M. L., Spires, T. L., Hyman, B. T., et al. (2007). Abnormal bundling and accumulation of F-actin mediates tau-induced neuronal degeneration in vivo. Nat. Cell Biol. 9, 139-148. doi: $10.1038 /$ ncb 1528

Ghosal, K., Vogt, D. L., Liang, M., Shen, Y., Lamb, B. T., and Pimplikar, S. W. (2009). Alzheimer's disease-like pathological features in transgenic mice expressing the APP intracellular domain. Proc. Natl. Acad. Sci. U.S.A. 106, 18367-18372. doi: 10.1073/pnas.0907652106

Giacobini, E., and Gold, G. (2013). Alzheimer disease therapy[mdash]moving from amyloid-[beta] to tau. Nat. Rev. Neurol. 9, 677-686. doi: 10.1038/nrneurol.2013.223

Glenner, G. G., and Wong, C. W. (1984). Alzheimer's disease: INITIAL report of the purification and characterization of a novel cerebrovascular amyloid protein. Biochem. Biophys. Res. Commun. 120, 885-890. doi: 10.1016/S0006-291X(84)80190-4

Goedert, M. (1993). Tau protein and the neurofibrillary pathology of Alzheimer's disease. Trends Neurosci. 16, 460-465. doi: 10.1016/0166-2236(93)90078-Z

Goedert, M., and Hasegawa, M. (1999). The tauopathies: toward an experimental animal model. Am. J. Pathol. 154, 1-6. doi: 10.1016/S0002-9440(10) 65242-X

Goedert, M., and Spillantini, M. G. (2017). Propagation of Tau aggregates. Mol. Brain 10, 18. doi: 10.1186/s13041-017-0298-7

Goedert, M., Spillantini, M. G., Hasegawa, M., Jakes, R., Crowther, R. A., and Klug, A. (1996). Molecular dissection of the neurofibrillary lesions of Alzheimer's disease. Cold Spring Harb. Symp. Quant. Biol. 61, 565-573. doi: 10.1101/SQB.1996.061.01.057

Goedert, M., Spillantini, M. G., Jakes, R., Rutherford, D., and Crowther, R. A. (1989a). Multiple isoforms of human microtubule-associated protein tau: sequences and localization in neurofibrillary tangles of Alzheimer's disease. Neuron 3, 519-526. doi: 10.1016/0896-6273(89)90210-9

Goedert, M., Spillantini, M. G., Potier, M. C., Ulrich, J., and Crowther, R. A. (1989b). Cloning and sequencing of the cDNA encoding an isoform of microtubule-associated protein tau containing four tandem repeats: differential expression of tau protein mRNAs in human brain. EMBO J. 8, 393-399.

Goedert, M., Wischik, C. M., Crowther, R. A., Walker, J. E., and Klug, A. (1988). Cloning and sequencing of the cDNA encoding a core protein of the paired helical filament of Alzheimer disease: identification as the microtubule-associated protein tau. Proc. Natl. Acad. Sci. U.S.A. 85, 4051-4055. doi: 10.1073/pnas.85.11.4051

Goldsbury, C., Mocanu, M. M., Thies, E., Kaether, C., Haass, C., Keller, P., et al. (2006). Inhibition of APP trafficking by tau protein does not increase the generation of amyloid-beta peptidesPresenilin/gammasecretase activity regulates protein clearance from the endocytic recycling compartment Presenilin-1-mediated retention of APP derivatives in early biosynthetic compartments A partial failure of membrane protein turnover may cause Alzheimer's disease: a new hypothesis. Traffic 7, 873-888. doi: 10.1111/j.1600-0854.2006.00434.x

Goutte, C., Tsunozaki, M., Hale, V. A., and Priess, J. R. (2002). APH-1 is a multipass membrane protein essential for the Notch signaling pathway in Caenorhabditis elegans embryos. Proc. Natl. Acad. Sci. U.S.A. 99, 775-779. doi: 10.1073/pnas.022523499

Greenberg, S. G., and Davies, P. (1990). A preparation of Alzheimer paired helical filaments that displays distinct tau proteins by polyacrylamide gel electrophoresis. Proc. Natl. Acad. Sci. U.S.A. 87, 5827-5831. doi: $10.1073 /$ pnas.87.15.5827

Grundke-Iqbal, I., Iqbal, K., Tung, Y. C., Quinlan, M., Wisniewski, H. M., and Binder, L. I. (1986). Abnormal phosphorylation of the microtubule-associated protein tau (tau) in Alzheimer cytoskeletal pathology. Proc. Natl. Acad. Sci. U.S.A. 83, 4913-4917. doi: 10.1073/pnas.83.13.4913

Gunawardena, S., Yang, G., and Goldstein, L. S. (2013). Presenilin controls kinesin1 and dynein function during APP-vesicle transport in vivo. Hum. Mol. Genet. 22, 3828-3843. doi: 10.1093/hmg/ddt237 
Hardy, J., and Allsop, D. (1991). Amyloid deposition as the central event in the aetiology of Alzheimer's disease. Trends Pharmacol. Sci. 12, 383-388. doi: 10.1016/0165-6147(91)90609-V

Hardy, J., and Selkoe, D. J. (2002). The Amyloid hypothesis of Alzheimer's Disease: progress and problems on the road to therapeutics. Science 297, 353-356. doi: $10.1126 /$ science. 1072994

Hardy, J. A., and Higgins, G. A. (1992). Alzheimer's disease: the amyloid cascade hypothesis. Science 256, 184-185. doi: 10.1126/science.1566067

Hasegawa, M. (2016). Molecular mechanisms in the pathogenesis of alzheimer's disease and tauopathies-prion-like seeded aggregation and phosphorylation. Biomolecules 6:e24. doi: 10.3390/biom6020024

Hasegawa, M., Smith, M. J., and Goedert, M. (1998). Tau proteins with FTDP-17 mutations have a reduced ability to promote microtubule assembly. FEBS Lett. 437, 207-210. doi: 10.1016/S0014-5793(98)01217-4

He, Z., Guo, J. L., McBride, J. D., Narasimhan, S., Kim, H., Changolkar, L., et al. (2017). Amyloid-beta plaques enhance Alzheimer's brain tau-seeded pathologies by facilitating neuritic plaque tau aggregation. Nat. Med. 24, 29-38. doi: $10.1038 / \mathrm{nm} .4443$

Hochgräfe, K., Sydow, A., and Mandelkow, E. M. (2013). Regulatable transgenic mouse models of Alzheimer disease: onset, reversibility and spreading of Tau pathology. FEBS J. 280, 4371-4381. doi: 10.1111/febs.12250

Hutton, M., Lendon, C. L., Rizzu, P., Baker, M., Froelich, S., Houlden, H., et al. (1998). Association of missense and 5'-splice-site mutations in tau with the inherited dementia FTDP-17. Nature 393, 702-705. doi: 10.1038/ 31508

Iqbal, K., Liu, F., and Gong, C. X. (2016). Tau and neurodegenerative disease: the story so far. Nat. Rev. Neurol. 12,15-27. doi: 10.1038/nrneurol.2015.225

Ishii, T., Kametani, F., Haga, S., and Sato, M. (1989). The immunohistochemical demonstration of subsequences of the precursor of the amyloid A4 protein in senile plaques in Alzheimer's disease. Neuropathol. Appl. Neurobiol. 15, 135-147. doi: 10.1111/j.1365-2990.1989.tb01216.x

Iwatsubo, T., Hasegawa, M., and Ihara, Y. (1994). Neuronal and glial tau-positive inclusions in diverse neurologic diseases share common phosphorylation characteristics. Acta Neuropathol. 88, 129-136. doi: 10.1007/BF00294505

Janson, J., Laedtke, T., Parisi, J. E., O’Brien, P., Petersen, R. C., and Butler, P. C. (2004). Increased risk of type 2 diabetes in Alzheimer disease. Diabetes 53, 474-481. doi: 10.2337/diabetes.53.2.474

Jellinger, K. A., Alafuzoff, I., Attems, J., Beach, T. G., Cairns, N. J., Crary, J. F., et al. (2015). PART, a distinct tauopathy, different from classical sporadic Alzheimer disease. Acta Neuropathol. 129, 757-762. doi: 10.1007/s00401-015-1407-2

Johnson, K. A., Schultz, A., Betensky, R. A., Becker, J. A., Sepulcre, J., Rentz, D., et al. (2015). Tau PET imaging in aging and early Alzheimer's disease. Ann. Neurol. 79, 110-119. doi: 10.1002/ana.24546

Kametani, F. (2008). epsilon-Secretase: reduction of amyloid precursor protein epsilon-site cleavage in Alzheimer's disease. Curr. Alzheimer Res. 5, 165-171. doi: $10.2174 / 156720508783954776$

Kametani, F., and Haga, S. (2015). Accumulation of carboxy-terminal fragments of APP increases phosphodiesterase 8B. Neurobiol. Aging 36, 634-637. doi: 10.1016/j.neurobiolaging.2014.09.029

Kametani, F., Usami, M., Tanaka, K., Kume, H., and Mori, H. (2004). Mutant presenilin (A260V) affects Rab8 in PC12D cell. Neurochem. Int. 44, 313-320. doi: 10.1016/S0197-0186(03)00176-1

Kang, J., Lemaire, H. G., Unterbeck, A., Salbaum, J. M., Masters, C. L., Grzeschik, K. H., et al. (1987). The precursor of Alzheimer's disease amyloid A4 protein resembles a cell-surface receptor. Nature 325, 733-736. doi: 10.1038/325733a0

Kim, J., Chakrabarty, P., Hanna, A., March, A., Dickson, D. W., Borchelt, D. R., et al. (2013). Normal cognition in transgenic BRI2-Abeta mice. Mol. Neurodegener. 8, 15. doi: 10.1186/1750-1326-8-15

Kim, J., Onstead, L., Randle, S., Price, R., Smithson, L., Zwizinski, C., et al. (2007). Abeta40 inhibits amyloid deposition in vivo. J. Neurosci. 27, 627-633. doi: 10.1523/JNEUROSCI.4849-06.2007

Klevanski, M., Herrmann, U., Weyer, S. W., Fol, R., Cartier, N., Wolfer, D. P., et al. (2015). The APP intracellular domain is required for normal synaptic morphology, synaptic plasticity, and hippocampus-dependent behavior. $J$. Neurosci. 35, 16018-16033. doi: 10.1523/JNEUROSCI.2009-15.2015

Kolata, G. (1985). Down syndrome-Alzheimer's linked. Science 230, 1152-1153. doi: $10.1126 /$ science. 2933807
Kondo, J., Honda, T., Mori, H., Hamada, Y., Miura, R., Ogawara, M., et al. (1988). The carboxyl third of tau is tightly bound to paired helical filaments. Neuron 1, 827-834. doi: 10.1016/0896-6273(88)90130-4

Kopan, R., and Ilagan, M. X. (2004). Gamma-secretase: proteasome of the membrane? Nat. Rev. Mol. Cell Biol. 5, 499-504. doi: 10.1038/nrm1406

Kosik, K. S., Orecchio, L. D., Binder, L., Trojanowski, J. Q., Lee, V. M., and Lee, G. (1988). Epitopes that span the tau molecule are shared with paired helical filaments. Neuron 1, 817-825. doi: 10.1016/0896-6273(88)90129-8

Kovacs, G. G. (2015). Invited review: neuropathology of tauopathies: principles and practice. Neuropathol. Appl. Neurobiol. 41, 3-23. doi: 10.1111/nan.12208

Krasemann, S., Madore, C., Cialic, R., Baufeld, C., Calcagno, N., El Fatimy, R., et al. (2017). The TREM2-APOE pathway drives the transcriptional phenotype of dysfunctional microglia in neurodegenerative diseases. Immunity 47, 566-581.e569. doi: 10.1016/j.immuni.2017.08.008

Lammich, S., Kojro, E., Postina, R., Gilbert, S., Pfeiffer, R., Jasionowski, M., et al. (1999). Constitutive and regulated alpha-secretase cleavage of Alzheimer's amyloid precursor protein by a disintegrin metalloprotease. Proc. Natl. Acad. Sci. U.S.A. 96, 3922-3927. doi: 10.1073/pnas.96.7.3922

Lee, V. M., Balin, B. J., Otvos, L. Jr., and Trojanowski, J. Q. (1991). A68: a major subunit of paired helical filaments and derivatized forms of normal Tau. Science 251, 675-678. doi: 10.1126/science. 1899488

Lee, V. M., Goedert, M., and Trojanowski, J. Q. (2001). Neurodegenerative tauopathies. Annu. Rev. Neurosci. 24, 1121-1159. doi: 10.1146/annurev.neuro.24.1.1121

Leyns, C. E. G., and Holtzman, D. M. (2017). Glial contributions to neurodegeneration in tauopathies. Mol. Neurodegener. 12, 50. doi: 10.1186/s13024-017-0192-x

Leyns, C. E. G., Ulrich, J. D., Finn, M. B., Stewart, F. R., Koscal, L. J., Remolina Serrano, J., et al. (2017). TREM2 deficiency attenuates neuroinflammation and protects against neurodegeneration in a mouse model of tauopathy. Proc. Natl. Acad. Sci. U.S.A. 114, 11524-11529. doi: 10.1073/pnas.1710311114

Li, Y., Rinne, J. O., Mosconi, L., Pirraglia, E., Rusinek, H., Desanti, S., et al. (2008). Regional analysis of FDG and PIB-PET images in normal aging, mild cognitive impairment, and Alzheimer's disease. Eur. J. Nuclear Med. Mol. Image 35, 2169-2181. doi: 10.1007/s00259-008-0833-y

Maestre, G., Ottman, R., Stern, Y., Gurland, B., Chun, M., Tang, M. X., et al. (1995). Apolipoprotein $\mathrm{E}$ and Alzheimer's disease: ethnic variation in genotypic risks. Ann. Neurol. 37, 254-259. doi: 10.1002/ana.410370217

Marciniak, E., Leboucher, A., Caron, E., Ahmed, T., Tailleux, A., Dumont, J., et al. (2017). Tau deletion promotes brain insulin resistance. J. Exp. Med. 214, 2257-2269. doi: 10.1084/jem.20161731

Masliah, E., Mallory, M., Alford, M., DeTeresa, R., Hansen, L. A., Mckeel, D. W. Jr., et al. (2001). Altered expression of synaptic proteins occurs early during progression of Alzheimer's disease. Neurology 56, 127-129. doi: 10.1212/WNL.56.1.127

Masters, C. L., Simms, G., Weinman, N. A., Multhaup, G., McDonald, B. L., and Beyreuther, K. (1985). Amyloid plaque core protein in Alzheimer disease and Down syndrome. Proc. Natl. Acad. Sci. U.S.A. 82, 4245-4249. doi: $10.1073 /$ pnas.82.12.4245

Miao, Y., Chen, J., Zhang, Q., and Sun, A. (2010). Deletion of tau attenuates heat shock-induced injury in cultured cortical neurons. J. Neurosci. Res. 88, 102-110. doi: $10.1002 / j n r .22188$

Nonaka, T., Watanabe, S. T., Iwatsubo, T., and Hasegawa, M. (2010). Seeded aggregation and toxicity of \{alpha\}-synuclein and tau: cellular models of neurodegenerative diseases. J. Biol. Chem. 285, 34885-34898. doi: 10.1074/jbc.M110.148460

Nukina, N., and Ihara, Y. (1986). One of the antigenic determinants of paired helical filaments is related to tau protein. J. Biochem. 99, 1541-1544. doi: 10.1093/oxfordjournals.jbchem.a135625

Okamura, N., and Yanai, K. (2017). Brain imaging: applications of tau PET imaging. Nat. Rev. Neurol. 13, 197-198. doi: 10.1038/nrneurol.2017.38

Oltersdorf, T., Ward, P. J., Henriksson, T., Beattie, E. C., Neve, R., Lieberburg, I., et al. (1990). The Alzheimer amyloid precursor protein. Identification of a stable intermediate in the biosynthetic/degradative pathway. J. Biol. Chem. 265, 4492-4497.

Ostrowitzki, S., Deptula, D., Thurfjell, L., Barkhof, F., Bohrmann, B., Brooks, D. J., et al. (2012). Mechanism of amyloid removal in patients with 
Alzheimer disease treated with gantenerumab. Arch. Neurol. 69, 198-207. doi: 10.1001/archneurol.2011.1538

Pera, M., Alcolea, D., Sánchez-Valle, R., Guardia-Laguarta, C., Colom-Cadena, M., Badiola, N., et al. (2013). Distinct patterns of APP processing in the CNS in autosomal-dominant and sporadic Alzheimer disease. Acta Neuropathol. 125, 201-213. doi: 10.1007/s00401-012-1062-9

Poorkaj, P., Bird, T. D., Wijsman, E., Nemens, E., Garruto, R. M., Anderson, L., et al. (1998). Tau is a candidate gene for chromosome 17 frontotemporal dementia. Ann. Neurol. 43, 815-825. doi: 10.1002/ana.410430617

Price, J. L., Mckeel, D. W. Jr., Buckles, V. D., Roe, C. M., Xiong, C., Grundman, M., et al. (2009). Neuropathology of nondemented aging: presumptive evidence for preclinical Alzheimer disease. Neurobiol. Aging 30, 1026-1036. doi: 10.1016/j.neurobiolaging.2009.04.002

Rapoport, M., Dawson, H. N., Binder, L. I., Vitek, M. P., and Ferreira, A. (2002). Tau is essential to $\beta$-amyloid-induced neurotoxicity. Proc. Natl. Acad. Sci. U.S.A. 99, 6364-6369. doi: 10.1073/pnas.092136199

Robakis, N. K., and Georgakopoulos, A. (2014). Allelic interference: a mechanism for trans-dominant transmission of loss of function in the neurodegeneration of Familial Alzheimer's Disease. Neurodegener. Dis. 13, 126-130. doi: 10.1159/000354241

Roberson, E. D., Scearce-Levie, K., Palop, J. J., Yan, F., Cheng, I. H., Wu, T., et al. (2007). Reducing endogenous tau ameliorates Amyloid B-Induced Deficits in an Alzheimer's disease mouse model. Science 316, 750-754. doi: $10.1126 /$ science. 1141736

Robert, J., Button, E. B., Yuen, B., Gilmour, M., Kang, K., Bahrabadi, A., et al. (2017). Clearance of beta-amyloid is facilitated by apolipoprotein $\mathrm{E}$ and circulating high-density lipoproteins in bioengineered human vessels. Elife 6:e29595. doi: 10.7554/eLife.29595

Rodrigues, E. M., Weissmiller, A. M., and Goldstein, L. S. (2012). Enhanced betasecretase processing alters APP axonal transport and leads to axonal defects. Hum. Mol. Genet. 21, 4587-4601. doi: 10.1093/hmg/dds297

Rovelet-Lecrux, A., Hannequin, D., Raux, G., Meur, N. L., Laquerrière, A., Vital, A., et al. (2006). APP locus duplication causes autosomal dominant early-onset Alzheimer disease with cerebral amyloid angiopathy. Nat. Genet. 38, 24-26. doi: $10.1038 / \mathrm{ng} 1718$

Roy, S., Zhang, B., Lee, V. M.-Y., and Trojanowski, J. Q. (2005). Axonal transport defects: a common theme in neurodegenerative diseases. Acta Neuropathol. 109, 5-13. doi: 10.1007/s00401-004-0952-x

Rusu, P., Jansen, A., Soba, P., Kirsch, J., Löwer, A., Merdes, G., et al. (2007). Axonal accumulation of synaptic markers in APP transgenic Drosophila depends on the NPTY motif and is paralleled by defects in synaptic plasticity. Eur. J. Neurosci. 25, 1079-1086. doi: 10.1111/j.1460-9568.2007.05341.x

Salloway, S., Sperling, R., Fox, N. C., Blennow, K., Klunk, W., Raskind, M., et al. (2014). Two phase 3 trials of bapineuzumab in mild-to-moderate Alzheimer's disease. N. Engl. J. Med. 370, 322-333. doi: 10.1056/NEJMoa1304839

SantaCruz, K., Lewis, J., Spires, T., Paulson, J., Kotilinek, L., Ingelsson, M., et al. (2005). Tau suppression in a neurodegenerative mouse model improves memory function. Science 309, 476-481. doi: 10.1126/science. 1113694

Schöll, M., Lockhart, S. N., Schonhaut, D. R., O’neil, J. P., Janabi, M., Ossenkoppele, R., et al. (2016). PET imaging of tau deposition in the aging human brain. Neuron 89, 971-982. doi: 10.1016/j.neuron.2016.01.028

Schwarz, A. J., Yu, P., Miller, B. B., Shcherbinin, S., Dickson, J., Navitsky, M., et al. (2016). Regional profiles of the candidate tau PET ligand 18F-AV1451 recapitulate key features of Braak histopathological stages. Brain 139, 1539-1550. doi: 10.1093/brain/aww023

Selkoe, D. J. (1991). The molecular pathology of Alzheimer's disease. Neuron 6, 487-498. doi: 10.1016/0896-6273(91)90052-2

Serrano-Pozo, A., Frosch, M. P., Masliah, E., and Hyman, B. T. (2011). Neuropathological alterations in Alzheimer disease. Cold Spring Harb. Perspect. Med. 1, a006189. doi: 10.1101/cshperspect.a006189

Shankar, G. M., Li, S., Mehta, T. H., Garcia-Munoz, A., Shepardson, N. E., Smith, I., et al. (2008). Amyloid-beta protein dimers isolated directly from Alzheimer's brains impair synaptic plasticity and memory. Nat. Med. 14, 837-842. doi: $10.1038 / \mathrm{nm} 1782$

Shen, J., and Kelleher, R. J., III (2007). The presenilin hypothesis of Alzheimer's disease: evidence for a loss-of-function pathogenic mechanism. Proc. Natl. Acad. Sci. U.S.A. 104, 403-409. doi: 10.1073/pnas.0608332104
Shi, Y., Yamada, K., Liddelow, S. A., Smith, S. T., Zhao, L., Luo, W., et al. (2017). ApoE4 markedly exacerbates tau-mediated neurodegeneration in a mouse model of tauopathy. Nature 549, 523-527. doi: 10.1038/nature24016

Shipton, O. A., Leitz, J. R., Dworzak, J., Acton, C. E. J., Tunbridge, E. M., Denk, F., et al. (2011). Tau Protein Is Required for Amyloid $\beta$ induced impairment of hippocampal long-term potentiation. J. Neurosci. 31, 1688-1692. doi: 10.1523/JNEUROSCI.2610-10.2011

Spillantini, M. G., Goedert, M., Crowther, R. A., Murrell, J. R., Farlow, M. R., and Ghetti, B. (1997). Familial multiple system tauopathy with presenile dementia: a disease with abundant neuronal and glial tau filaments. Proc. Natl. Acad. Sci. U.S.A. 94, 4113-4118. doi: 10.1073/pnas.94.8.4113

Spillantini, M. G., Murrell, J. R., Goedert, M., Farlow, M. R., Klug, A., and Ghetti, B. (1998). Mutation in the tau gene in familial multiple system tauopathy with presenile dementia. Proc. Natl. Acad. Sci. USA. 95, 7737-7741. doi: 10.1073/pnas.95.13.7737

SvedruŽić, Ž. M., Popović, K., and Šendula-Jengić, V. (2015). Decrease in catalytic capacity of gamma-secretase can facilitate pathogenesis in sporadic and Familial Alzheimer's disease. Mol. Cell. Neurosci. 67, 55-65. doi: 10.1016/j.mcn.2015.06.002

Szpankowski, L., Encalada, S. E., and Goldstein, L. S. (2012). Subpixel colocalization reveals amyloid precursor protein-dependent kinesin-1 and dynein association with axonal vesicles. Proc. Natl. Acad. Sci. U.S.A. 109, 8582-8587. doi: 10.1073/pnas.1120510109

Tai, L. M., Ghura, S., Koster, K. P., Liakaite, V., Maienschein-Cline, M., Kanabar, P., et al. (2015). APOE-modulated A $\beta$-induced neuroinflammation in Alzheimer's disease: current landscape, novel data, and future perspective. J. Neurochem. 133, 465-488. doi: 10.1111/jnc. 13072

Takahashi, M., Miyata, H., Kametani, F., Nonaka, T., Akiyama, H., Hisanaga, S.-I., et al. (2015). Extracellular association of APP and tau fibrils induces intracellular aggregate formation of tau. Acta Neuropathol. 129, 895-907. doi: 10.1007/s00401-015-1415-2

Takasugi, N., Tomita, T., Hayashi, I., Tsuruoka, M., Niimura, M., Takahashi, Y., et al. (2003). The role of presenilin cofactors in the gamma-secretase complex. Nature 422, 438-441. doi: 10.1038/nature01506

Tamayev, R., Matsuda, S., Arancio, O., and D'adamio, L. (2012). beta- but not gamma-secretase proteolysis of APP causes synaptic and memory deficits in a mouse model of dementia. EMBO Mol. Med. 4, 171-179. doi: 10.1002/emmm.201100195

Taniguchi-Watanabe, S., Arai, T., Kametani, F., Nonaka, T., Masuda-Suzukake, M., Tarutani, A., et al. (2016). Biochemical classification of tauopathies by immunoblot, protein sequence and mass spectrometric analyses of sarkosyl-insoluble and trypsin-resistant tau. Acta Neuropathol. 131, 267-280. doi: 10.1007/s00401-015-1503-3

Tesco, G., Ginestroni, A., Hiltunen, M., Kim, M., Dolios, G., Hyman, B. T., et al. (2005). APP substitutions V715F and L720P alter PS1 conformation and differentially affect Abeta and AICD generation. J. Neurochem. 95, 446-456. doi: $10.1111 / j .1471-4159.2005 .03381 . x$

Ulland, T. K., Song, W. M., Huang, S. C.-C., Ulrich, J. D., Sergushichev, A., Beatty, W. L., et al. (2017). TREM2 maintains microglial metabolic fitness in Alzheimer's Disease. Cell 170, 649-663.e613. doi: 10.1016/j.cell.2017.07.023

Vassar, R., Bennett, B. D., Babu-Khan, S., Kahn, S., Mendiaz, E. A., Denis, P., et al. (1999). Beta-secretase cleavage of Alzheimer's amyloid precursor protein by the transmembrane aspartic protease BACE. Science 286, 735-741. doi: $10.1126 /$ science. 286.5440 .735

Walker, E. S., Martinez, M., Brunkan, A. L., and Goate, A. (2005). Presenilin 2 familial Alzheimer's disease mutations result in partial loss of function and dramatic changes in Abeta $42 / 40$ ratios. J. Neurochem. 92, 294-301. doi: 10.1111/j.1471-4159.2004.02858.x

Weidemann, A., Eggert, S., Reinhard, F. B., Vogel, M., Paliga, K., Baier, G., et al. (2002). A novel epsilon-cleavage within the transmembrane domain of the Alzheimer amyloid precursor protein demonstrates homology with Notch processing. Biochemistry 41, 2825-2835. doi: 10.1021/bi015794o

Wiley, J. C., Hudson, M., Kanning, K. C., Schecterson, L. C., and Bothwell, M. (2005). Familial Alzheimer's disease mutations inhibit gamma-secretasemediated liberation of beta-amyloid precursor protein carboxy-terminal fragment. J. Neurochem. 94, 1189-1201. doi: 10.1111/j.1471-4159.2005.03266.x William, C. M., Andermann, M. L., Goldey, G. J., Roumis, D. K., Reid, R. C., Shatz, C. J., et al. (2012). Synaptic plasticity defect following visual deprivation 
in Alzheimer's disease model transgenic mice. J. Neurosci. 32, 8004-8011. doi: 10.1523/JNEUROSCI.5369-11.2012

Wischik, C. M., Novak, M., Edwards, P. C., Klug, A., Tichelaar, W., and Crowther, R. A. (1988a). Structural characterization of the core of the paired helical filament of Alzheimer disease. Proc. Natl. Acad. Sci. U.S.A. 85, 4884-4888. doi: $10.1073 /$ pnas.85.13.4884

Wischik, C. M., Novak, M., Thøgersen, H. C., Edwards, P. C., Runswick, M. J., Jakes, R., et al. (1988b). Isolation of a fragment of tau derived from the core of the paired helical filament of Alzheimer disease. Proc. Natl. Acad. Sci. U.S.A. 85, 4506-4510. doi: 10.1073/pnas.85.12.4506

Woodruff, G., Reyna, S. M., Dunlap, M., Van Der Kant, R., Callender, J. A., Young, J. E., et al. (2016). Defective transcytosis of APP and lipoproteins in human iPSC-derived neurons with familial Alzheimer's disease mutations. Cell Rep. 17, 759-773. doi: 10.1016/j.celrep.2016.09.034

Xia, D., Watanabe, H., Wu, B., Lee, S. H., Li, Y., Tsvetkov, E., et al. (2015). Presenilin-1 knockin mice reveal loss-of-function mechanism for familial Alzheimer's disease. Neuron 85, 967-981. doi: 10.1016/j.neuron.2015.02.010

Xu, T. H., Yan, Y., Kang, Y., Jiang, Y., Melcher, K., and Xu, H. E. (2016a). Alzheimer's disease-associated mutations increase amyloid precursor protein resistance to gamma-secretase cleavage and the Abeta42/Abeta40 ratio. Cell Discov. 2:16026. doi: 10.1038/celldisc.2016.26

Xu, W., Weissmiller, A. M., White, J. A. II., Fang, F., Wang, X., Wu, Y., et al. (2016b). Amyloid precursor protein-mediated endocytic pathway disruption induces axonal dysfunction and neurodegeneration. J. Clin. Invest. 126, 1815-1833. doi: 10.1172/JCI82409

Yamada, K., Patel, T. K., Hochgräfe, K., Mahan, T. E., Jiang, H., Stewart, F. R., et al. (2015). Analysis of in vivo turnover of tau in a mousemodel of tauopathy. Mol.
Neurodegener. 10, 55. doi: 10.1186/s13024-015-0052-5

Yoshikawa, K., Aizawa, T., and Hayashi, Y. (1992). Degeneration in vitro of post-mitotic neurons overexpressing the Alzheimer amyloid protein precursor. Nature 359, 64-67. doi: 10.1038/359064a0

Yu, G., Nishimura, M., Arawaka, S., Levitan, D., Zhang, L., Tandon, A., et al. (2000). Nicastrin modulates presenilin-mediated notch/glp-1 signal transduction and betaAPP processing. Nature 407, 48-54. doi: 10.1038/35024009

Zempel, H., and Mandelkow, E. (2014). Lost after translation: missorting of Tau protein and consequences for Alzheimer disease. Trends Neurosci. 37, 721-732. doi: 10.1016/j.tins.2014.08.004

Zhou, L., McInnes, J., Wierda, K., Holt, M., Herrmann, A. G., Jackson, R. J., et al. (2017). Tau association with synaptic vesicles causes presynaptic dysfunction. Nat. Commun. 8:15295. doi: 10.1038/ncomms15295

Zlokovic, B. V. (2013). Cerebrovascular effects of apolipoprotein e: implications for alzheimer disease. JAMA Neurol. 70, 440-444. doi: 10.1001/jamaneurol.2013.2152

Conflict of Interest Statement: The authors declare that the research was conducted in the absence of any commercial or financial relationships that could be construed as a potential conflict of interest.

Copyright $\odot 2018$ Kametani and Hasegawa. This is an open-access article distributed under the terms of the Creative Commons Attribution License (CC BY). The use, distribution or reproduction in other forums is permitted, provided the original author(s) and the copyright owner are credited and that the original publication in this journal is cited, in accordance with accepted academic practice. No use, distribution or reproduction is permitted which does not comply with these terms. 